\title{
Control of Inverter-Based Micro-Grids
}

T.C. Green and M. Prodanović

\begin{abstract}
The predicted growth of small-scale non-50/60Hz power sources and the desire to be able to support loads independently of the public electricity grid requires the development of inverter-based micro-grids. Power electronic interfaces have very different characteristics to conventional electrical machines and, therefore, different operation, control and protection schemes are required. Attention also needs to be given to the dominance of single-phase harmonically-distorting loads in some networks and control schemes put in place that maintain voltage quality. A control scheme that exploits the controllability of inverters to operate a microgrid and provide good power quality is examined and compared with both traditional power systems and with control of DC/DC power converters. The limitations of communication and control bandwidth are discussed. Experimental results are used to illustrate the performance that can be achieved with various combinations of linear and non-linear, three-phase and single-phase loads.
\end{abstract}

\section{Introduction}

Micro-grids are thought to be a likely direction for evolution of power systems that incorporate distributed generation. The term micro-grid is not strictly defined and covers a wide range of possible systems [1, 2, 3]. Here the term is taken to mean a subset of a power distribution system that contains sufficient energy sources to supply most or all of the local load. The micro-grid is thus able to operate with only a small power exchange with the rest of the system and at times can separate from the public system and run as an independent island. A micro-grid differs from existing island power systems (both physical islands and electrical islands such as offshore oil/gas platforms, ships and aircraft) in that connection to and disconnection from a public grid is a regular event. It is anticipated that the loads will be normal domestic and commercial consumer loads. As such, large numbers of single-phase diode rectifier loads are anticipated and the supply current is expected to be unbalanced and distorted. In some island systems, for instance an oil platform, the initiation of major loads (hoists, pumps etc.) can be anticipated and the generation resources can be put in readiness for the transient. This may be possible in some sorts of micro-grid but, if not, load forecasting is likely to be important and demand-side participation in control may be needed.

The generating technology found in a micro-grid may take many forms and an individual micro-grid is likely to include a mixture of these. Sources may be small, such as domestic CHP systems or roof-top photovoltaic panels, or relatively large, such as office-block-scale CHP using gas-turbines or reciprocating engines. Sources may be intermittent (photovoltaic and heat-led CHP) or fully controllable (electric-led CHP or simple diesel/gas fuelled generators). To make best use of intermittent sources and/or to provide security, a micro-grid may include a storage element such as a flywheel, battery or hydrogen electrolysis/fuel-cell system. Relatively large generators, especially existing peak-lopping diesel generators that are turned to micro-grid duty, are likely to be conventional synchronous machines generating at $50 / 60 \mathrm{~Hz}$ three-phase. Newer technology will be different. Some sources are natural DC sources, such as photovoltaics, fuel-cells and batteries. Others are variable frequency or high frequency AC such as micro-turbines and flywheels. The non-50/60 Hz sources will need to be interfaced to the grid via inverters.

The form the micro-grid takes and the type of loads supplied will have a large impact on the operating and control regime of the system. As yet, there are no established standard operating schemes and it may never be possible or desirable to have a universally applied method. This paper will describe the operation and control of a micro-grid for a particular situation, namely, a micro-grid that is formed of a relatively small number of generation sources that are interfaced to the grid through inverters and expected to supply unbalanced and distorting load current.

\section{The Power Park}

The example micro-grid system will be a power park. A power park consists of several power sources in relatively close proximity used to improve the electricity service to a group of customers. The customers may be a retail park, shopping mall or group of office buildings. If these are new consumers the power park may be motivated by network congestion or power shortages. Other motivations might be the wish to install co- 
generation or to provide premium power. The premium aspect would be the ability to continue supplying high value customers in the event of outage of the public grid or voltage sag. It might also mean avoidance of other power quality problems such as waveform distortion, flicker or swell. The improved power quality might come about from a lowered supply impedance, active management (such as active filtering) and/or disconnection from the public grid when the grid is deemed to be the source of the problem. Because some system operators presently do not allow distributed generators to control the voltage at the point of common connection, some of the power quality benefits may only be available when the micro-grid is running as an island. For increased reliability, flexibility and efficiency (when running part-load) several generators are required.

The power park might be owned by a landlord, a building services company, the consumers themselves or the existing utility company. Power export to the public grid might or might not be used whatever the ownership of the generation. Micro-grids in general may have a variety of owners of generation but the power park variant is likely to see a single owner or a single operator. Further, the generators will be in groups that are physically and electrically close together. The generation technology may be a mix of traditional electrical machines and inverters.

There are several possible operating modes of the power park:

1. Grid-connected operation with fixed local generation. The grid connection will see a fluctuating power flow as loads change. The power flow could be in either direction.

2. Grid-connected operation with load following local generation. The grid will see a fixed power flow which might be import (to cover short fall of local generation), export (to sell excess capacity) or zero (floating of the micro-grid but with a connection maintained to cover contingencies)

3. Island Operation. The local generation will load follow, possibly using storage or demand side participation to increase security.

The operation and control issues to be faced are:

1. How to share steady-state load between generating sets

2. How to share transient load between sets

3. How to switch seamlessly from grid-connected to island operation

4. How to incorporate additional features such as active management of waveform quality

\section{Characteristics of Electrical Machines and Inverters}

The history of power system generation is the history of the synchronous machine and the characteristics of this machine have influenced the development of other aspects of the system. For instance, protection schemes rely on the short-term over current rating of an electrical machine (resulting from its large thermal mass) to provide the fault current necessary to discriminate faults. In turn, the required clearance times for faults are dictated by the over-swing and loss of synchronism characteristics of machines. On the other hand, electronic power converters are well established in the fields of OEM power supplies and industrial drives but have not influenced the development of traditional power systems. Electronic power converters have very different characteristics to electrical machines and would have directed engineers toward a very different transmission and distribution system.

The relevant characteristics of electrical machines are:

1. Operate as voltage sources whose amplitude can be adjusted. The adjustment is normally part of a closed-loop excitation control scheme with a relatively low bandwidth.

2. Sine-wave voltage is a feature designed into the construction of the machine. The total harmonic distortion (THD) of the voltage is low. Distortion in the load current will increase the distortion in the voltage to an extent dependent on the source impedance.

3. The short-circuit current is high because the source impedance is low and no current limiting is employed.

4. The current rating is set by temperature rise of the winding insulation. The thermal time-constant of the winding and surrounding steel is relatively large and a useful short-term rating is available. Fault currents of as much as 10 times the steady-state maximum can be sustained for several mains cycles.

5. Real power exchange is dictated by the torque applied to shaft. Steady-state load sharing can be applied by a closed-loop governor setting that makes power output a function of the (common) system frequency. This is a designed in feature of the governor system but it is similar to the natural tendency for the speed of the prime mover to droop when electrical load is drawn. 
The corresponding characteristics of inverters are:

1. Operate as voltage sources (although current source versions are known) with near instantaneous and independent control of the magnitude of each phase.

2. Sine-wave voltage can be achieved through use of a suitable reference waveform and modulator but any shape can be used at will. Alternatively, closed-loop current regulation can be applied to achieve various current waveforms. The low-frequency spectrum of an inverter is well controlled but the switching action of the inverter produces high frequency distortion that can only be addressed through filtering.

3. Potential short-circuit current is high but protection against it must be provided in the form of current limiting action.

4. The current rating is set by the temperature rise of the semiconductors. The thermal time-constant of the semiconductor is very short and large over-currents cause device failure in considerably less than $1 \mathrm{~ms}$. The cooling system also has a relatively short thermal time-constant and so even moderate overcurrents can only be tolerated for short periods unless the inverter has been over-rated to accommodate them.

5. Real power exchange is dictated by the references applied to the control system (subject to the DC-link being able to source or sink this power).

There are several low-power application areas where electronic power converters are used for power distribution such as in telecommunication systems and large computers [4]. These power systems often consist of several DC power supplies running in parallel. The systems that have developed here are quite different from public AC power grids. The operating schemes are hierarchical control loops that actively share power between modules through distribution of current demand signals. The current demand signals are arranged to ensure that modules are not subjected to fault currents beyond their ratings and the overall system has a limited fault current that causes collapse of the system voltage.

The control and filtering functions required to supplement an inverter have a significant effect on system performance. The switching frequency of an inverter is limited by the power loss (due to switching) that can be accommodated within the cooling system. It may also be limited by the requirement for high efficiency. The switching frequency is likely to be between $5 \mathrm{kHz}$ and $20 \mathrm{kHz}$. The control system will be a discrete time controller (implemented on a DSP) and will have a sample rate equal to the switching frequency or a convenient factor of it. Thus, the control bandwidth for the inverter will be around $1 \mathrm{kHz}$ to $5 \mathrm{kHz}$. The second issue is that the switching frequency component of the inverter voltage will need to be attenuated. A first-order inductive filter is an obvious choice because an interface inductor is in any case necessary to couple a voltage source inverter to a voltage grid. However, a first-order filter would require a large inductor to achieve sufficient attenuation and so the filter is likely to be second-order LC. An interface inductor, coupling transformer or line inductance may also be present so the filter is, explicitly or implicitly, third-order LCL. Figure 1 shows the filter types and Figure 2 the frequency spectrum. It can be seen that the transition region of the filter, which includes the resonant frequency of the high order filters, is likely to lie near the upper limit of the controller bandwidth. This is problematic. There is barely enough control bandwidth to suppress the filter resonance. Placing the resonance safely above the controller frequency limit is not feasible because insufficient filter attenuation would be achieved. Reducing the resonant frequency to well within the control bandwidth will require physically large components and will make the system response sluggish above that frequency.

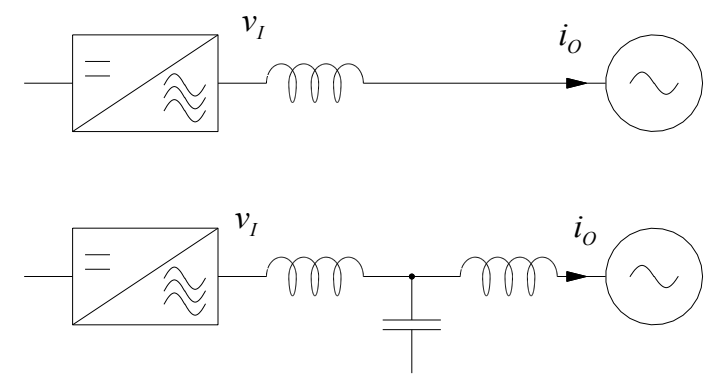

Figure 1. First- and third-order filters for attenuation of switching frequency voltage component 


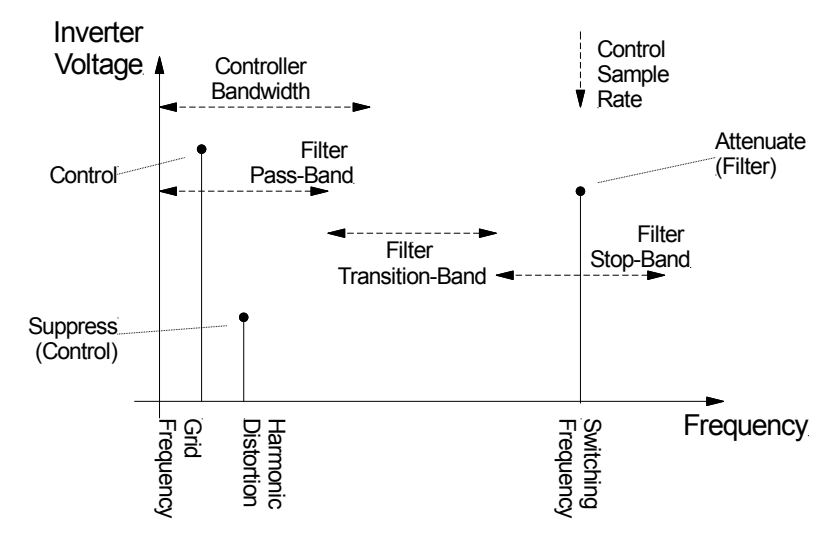

Figure 2. Frequency Spectrum of Inverter Voltage and Control Bandwidth

\section{Control of an Inverter for Power Export}

\subsection{Grid-connected Mode}

In grid-connected mode the objective is to export a controlled amount of power into the established voltage. This mode of operation has been extensively examined for power flow predominantly in the opposite direction under the guise of active rectifiers [5]. Most active rectifiers employ simple first-order filters (because power quality in the medium frequency range may not be particularly important) but second-order filters are also reported. Control of the exported power is through control of the in-phase component of current. Phase-locked loop (PLL) techniques are used to ensure synchronism [6]. Control in $d q$-axis (synchronous reference frame) form is usually preferred to magnitude-angle form. The current demands are generated from the power demands using the local voltage magnitude (available from the PLL). The power demands themselves come from the micro-grid supervisor (MGS) with the exception of photovoltaic and heat-led CHP sources which generate autonomously. The MGS will operate either to run the generators at fixed output (presumably optimum in some sense) or load following so as to regulate export from or import to the micro-grid. The overall control structure will be similar to Figure 3. The current is controlled in closed-loop form. The current references ( $d$ - and $q$-axes) are set on the basis of the required real and reactive powers. Strictly speaking, the power is set open-loop but the closed-loop current control ensures proper output power levels and power sharing between parallel units.

Figure 3 shows some standard inverter control techniques in addition to the simple current-control-loop. These are the addition of decoupling terms to compensate the natural coupling between $d$ - and $q$-axes (introduced by the filter reactance) and the feed-forward of the capacitor voltage into the current control-loop. For clarity, Figure 3 omits terms that might be added to compensate variation of the DC-link voltage of the inverter. The grid voltage may not be available for monitoring so alternative connections for the PLL are shown. Because each inverter controls its output current, current sharing and power sharing are assured according to the demands established by the MGS. The design of the controller and the design of the filter need to be considered together in order to establish good attenuation of both high and low frequency interference [7]. Controllers implemented in discrete time will also require additional decoupling terms [8].

Public electricity grids (at distribution voltage levels) often have significant harmonic distortion of the voltage. Choosing to control the output current of the inverter in an explicit current control-loop has the advantage of making the inverter a high impedance path that prevents flow of harmonic currents due to grid voltage distortion. (The filter capacitor does provide a path for harmonic currents and this must be account for in selecting its value). In contrast, a voltage source synchronous machine will present a low-impedance path to non-triplen harmonics.

Thought must be given how the voltage magnitude signal is used in the power calculation. The current calculated as necessary to export constant power will be harmonically distorted if the voltage is harmonically distorted. It may be preferred low-pass filter the calculated current reference to remove harmonic terms. The consequence of this is that the power export will contain ripple at frequencies related to the voltage harmonics. In other words, if the voltage is distorted there are three choices: (i) export undistorted current but distorted power; (ii) export undistorted power but distorted current or (iii) suffer some degree of distortion to both current 
and power. Figure 3 shows the current demand fed through a low-pass filter to ensure undistorted current references (option (i)).

It would be possible to set all inverters to export balanced fundamental-frequency-only current. However, the single-phase diode-rectifier loads will still required unbalanced and harmonic current components and these will have to be provided by any machines on the micro-grid or by the public grid. Drawing these components through significant line impedances will worsen the voltage distortion. Drawing a high proportion of distortion current from the public grid may be disallowed by the utility operator or by regulations.

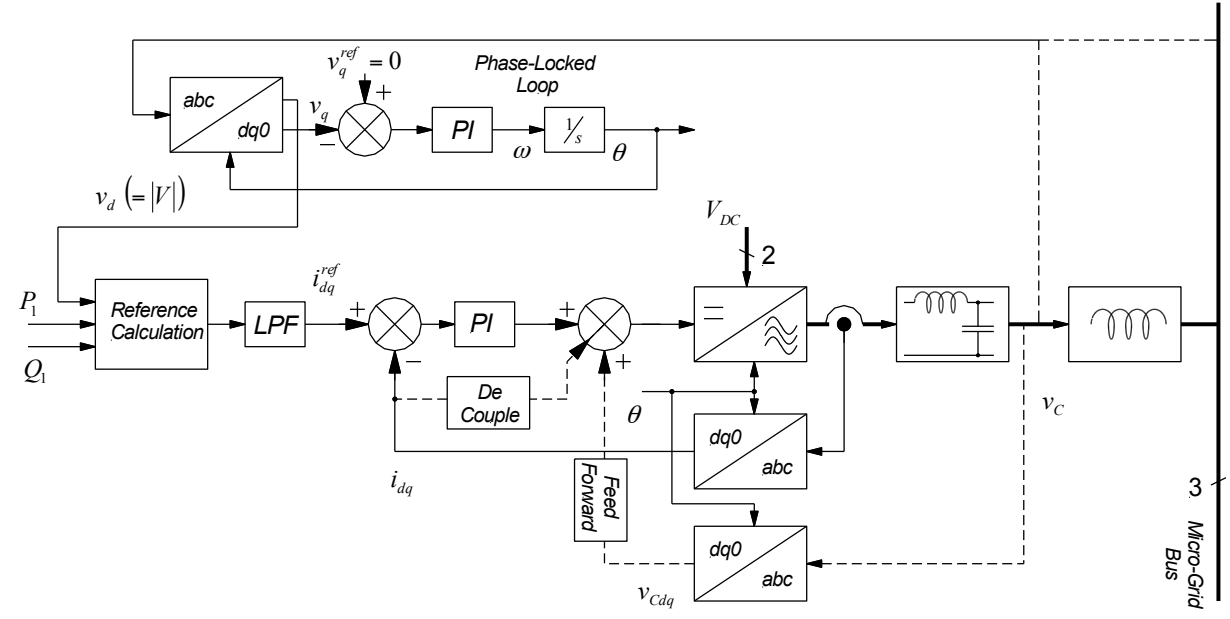

Figure 3. Control Structure of Power Export in Grid-Connected Mode (bold lines represent power connections; light lines represent signal connections and dashed lines are optional connections).

To achieve good voltage quality for local consumers extra control functions can be added. The voltage at the filter capacitor can be sensed and filtered to identify the harmonic distortion. This feedback is used to generate a current reference to add to the active and reactive current references in order to correct the distortion. (The terms reactive current and reactive power are here used to refer to the quadrature component of fundamental frequency current and its associated reactive power). Figure 4 shows a suitable control structure. It requires that there is some significant impedance (at harmonic frequencies) between the filter and the voltage source of the public grid in order that there can be some influence over the local voltage. This is one approach to incorporating active power filter functionality into a power export inverter. Such techniques generally require a greater degree of instrumentation that the simple inverter controllers and a cost and complexity penalty is paid for this.

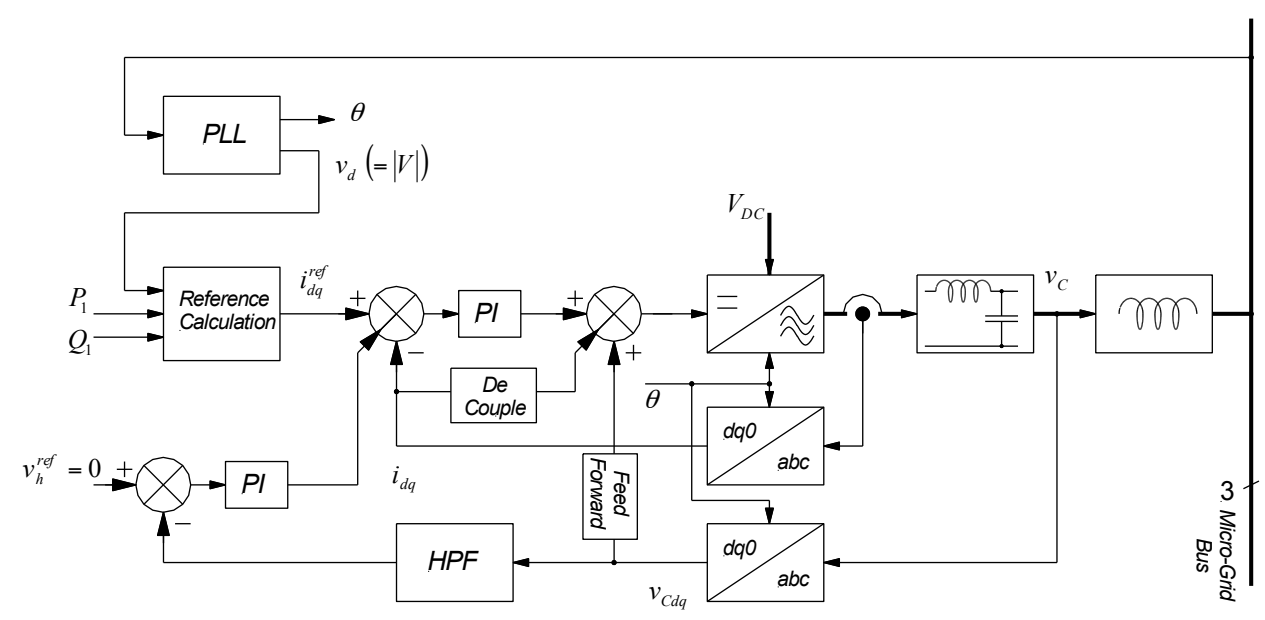

Figure 4. Grid-Connected Mode with Additional Distortion Suppression

If control of the voltage magnitude at the point of common coupling is allowed (or if a local bus separated from the utility grid is arranged for supply of premium loads) then control of the whole of the voltage spectrum (up to the control bandwidth limit) is possible. One such scheme has been reported [9] using a technique known as repetitive control to suppress distortion. 


\subsection{Island Mode}

Whereas the task in grid-connected mode is to control current into an established voltage, the task in island mode is to establish that voltage. Figure 5 shows the obvious approach of closing a control loop on the second order plant.

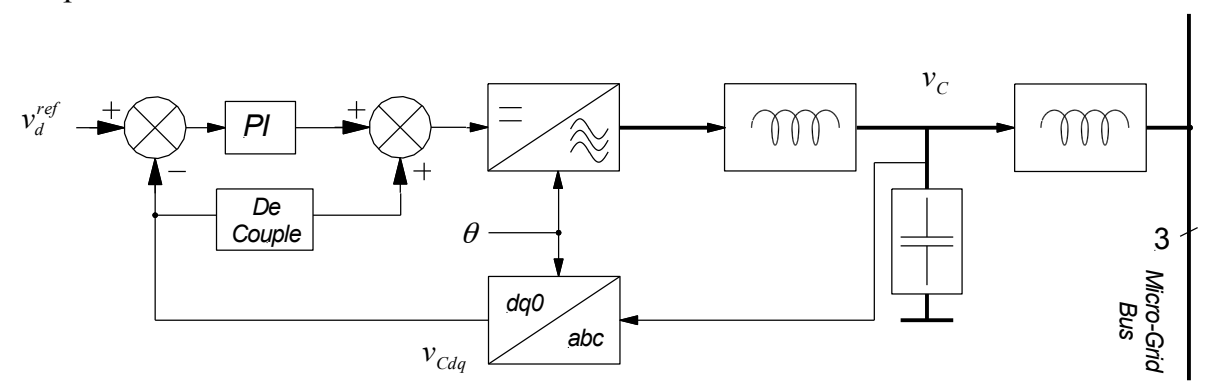

Figure 5. Single-Loop Control of Voltage for Island Mode

There are short comings to this approach that have long been recognised in switch-mode power supplies and machine drives $[10,11]$ :

1. Although the voltage is controlled, there is no explicit control of current and large transient currents (dangerous to the semiconductors) can occur.

2. The plant is not simply second order: it includes a distribution network and loads. It can be viewed as a second order plant with a disturbance current. In addition the plant parameters may not be known accurately.

3. Feed-forward of load current disturbances can be readily incorporated.

The standard alternative is to use nested control loops, Figure 6. The plant is considered as two first-order systems. They are reasonably well decoupled because of their different time constants. An inner current-controlloop is formed around the inductor and is arranged to have a fast response. This subsystem behaves as a near perfect controlled current from the point of view of the outer voltage-control-loop. If the current demand generated by the outer loop is limited then the inverter will not be subjected to excessive current. The controller is again shown in a rotating reference frame. The angle used to convert between $a b c$ and $d q$ coordinates can be obtained from an oscillator that sets the system frequency. Further improvement in transient response to load changes can be obtained by feed-forward of the load (disturbance) current.

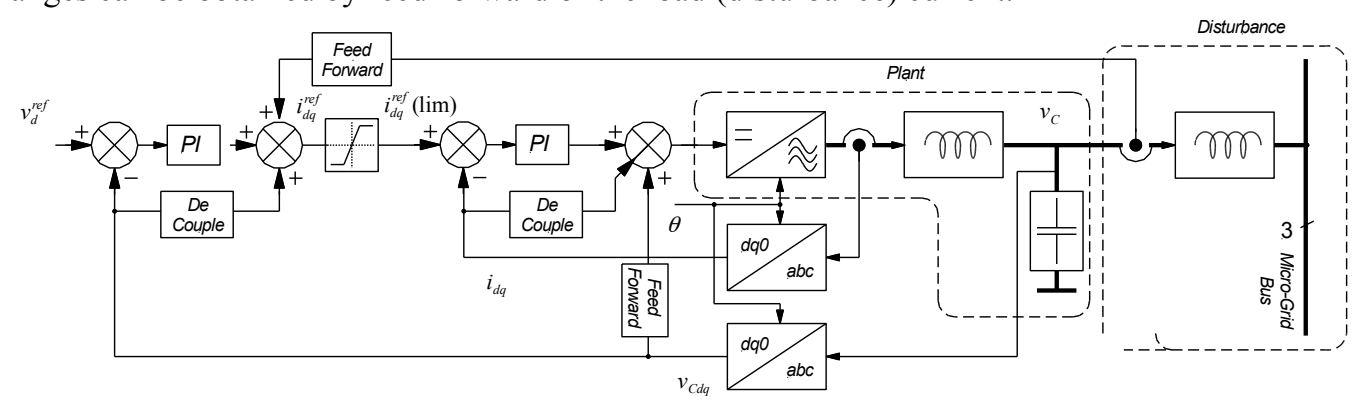

Figure 6. Nested voltage and current control loops used to control grid voltage.

Another advantage of the nested control-loop approach with its explicit current demand is that it lends itself to current (and power) sharing between parallel modules [12]. This is illustrated in Figure 7. The technique can be readily applied to power converters in very close proximity. However, when there is some distance between them then the current demand signals need to be transmitted over an explicit communication channel. In addition, a synchronising signal will also need to be communicated to all inverters. The bandwidth of the communication links would need to be above $100 \mathrm{~kb} / \mathrm{s}$ to avoid degrading the performance of the controllers. 


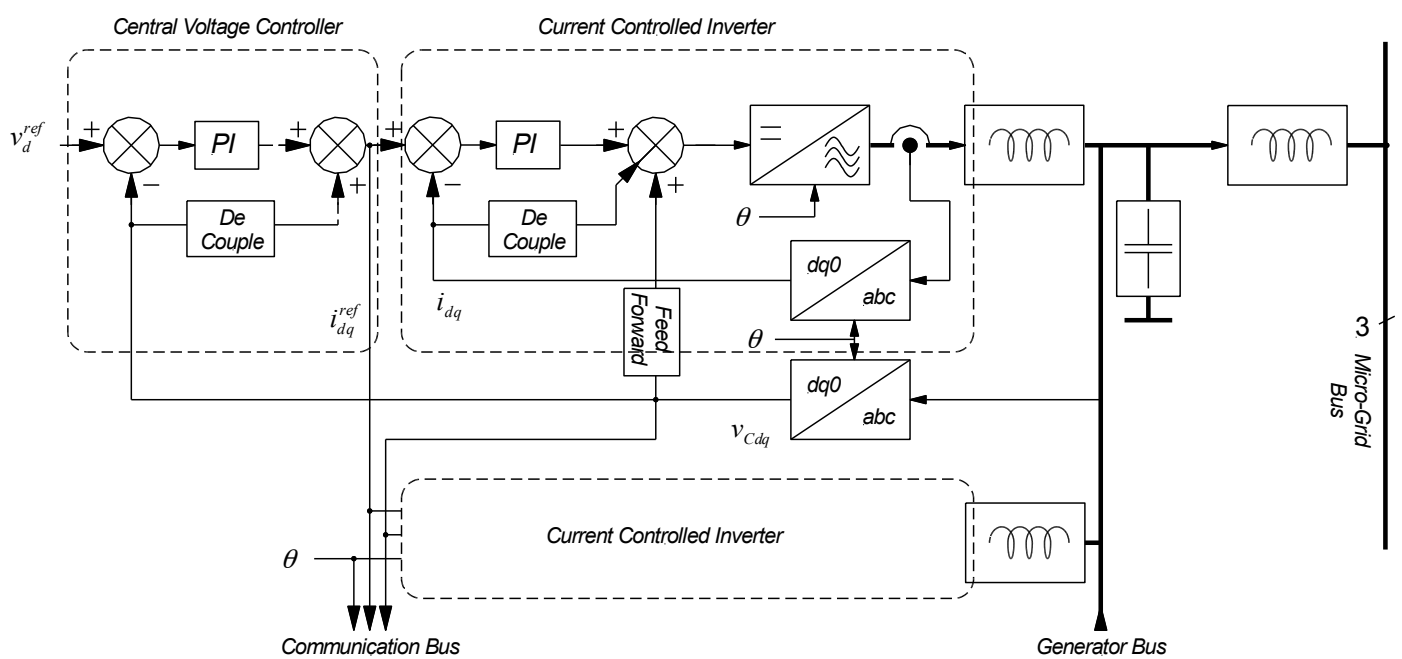

Figure 7. Multiple Inverters with Individual Current Control Loops

An alternative approach to providing sharing between parallel modules that is popular in modular DC power supplies is the master-slave approach $[13,14]$. Nested control-loops are used for the master power converter (or inverter). The output current of this converter (or, alternatively, the total load current) is measured by the slave units and used as their current reference. Thus the slaves attempt to supply the same current as the master (or a scaled version of that current) and steady-state sharing is achieved. The master-slave approach can be readily applied to inverters and AC systems by forming the control loops in a rotating reference frame, Figure 8 or even a stationary reference frame [13]. The asymmetry of the system leads the master converter to take on most of the transient duty and most of the supply of unbalanced current. This is principally because of the limited bandwidth or noise filtering in the distribution path of the current sharing signal. (Negative-sequence unbalance currents appear as double frequency terms in a rotating reference frame, a potential disadvantage of applying $d q$-axis control to unbalanced systems. The zero-sequence terms have not been shown in these diagrams but would need to be controlled also if four-leg inverters and a four-wire generator bus were used.) This effect is heightened if the bandwidth of the communication channel for the slave current demand has been deliberately limited.

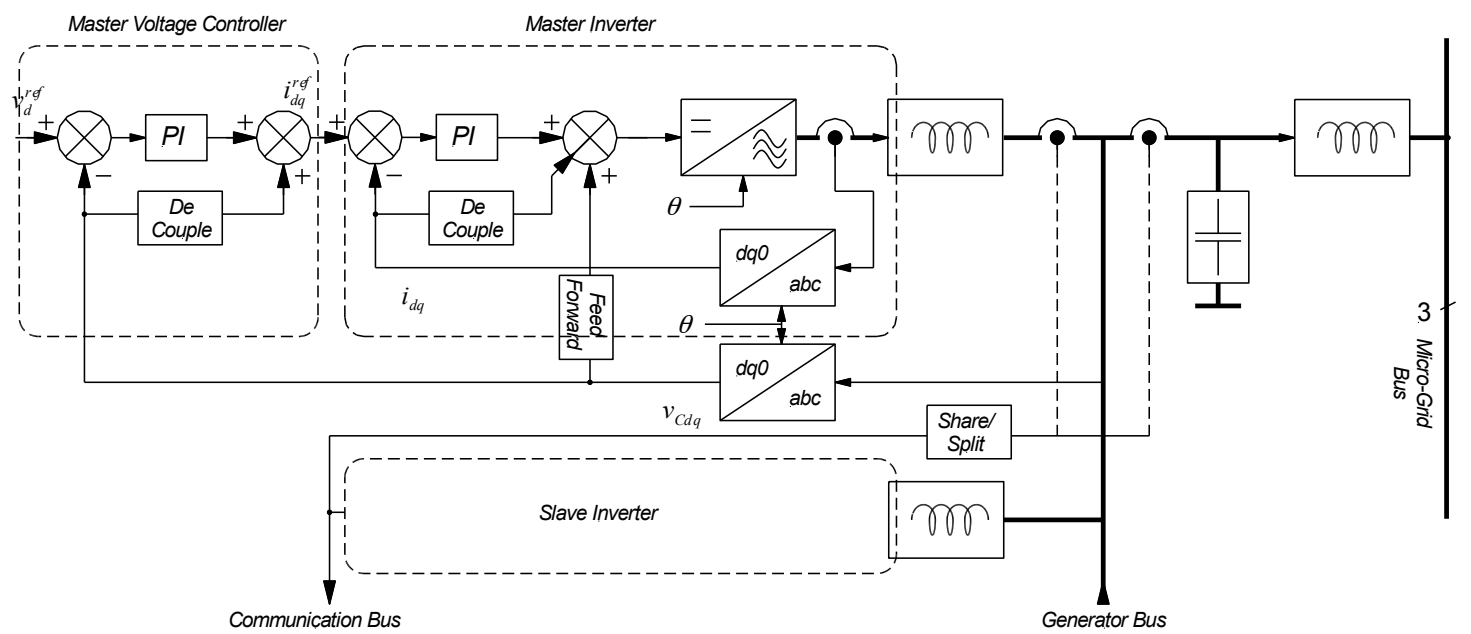

Figure 8. Master-Slave Arrangement of Multiple Inverters

Because the transient capacity of an inverter is limited (in comparison to electrical machines) it would be helpful to provide transient-state sharing between close inverters. This can be achieved without high bandwidth communication links by partitioning the frequency spectrum and applying different controllers to different partitions, Figure 9. Steady-state sharing of power is achieved through control of the low-frequency portion of the voltage in a control system similar to Figure 6 . The current demand for distribution to the various modules is in $d q$-form and limited in bandwidth to around $500 \mathrm{~Hz}$ (perhaps $10 \mathrm{~kb} / \mathrm{s}$ ). Local control-loops (for each inverter) that sense the local voltage then act to reduce the harmonic distortion (at relatively high frequency) toward zero. This gives rise to the term distributed control [13]. 


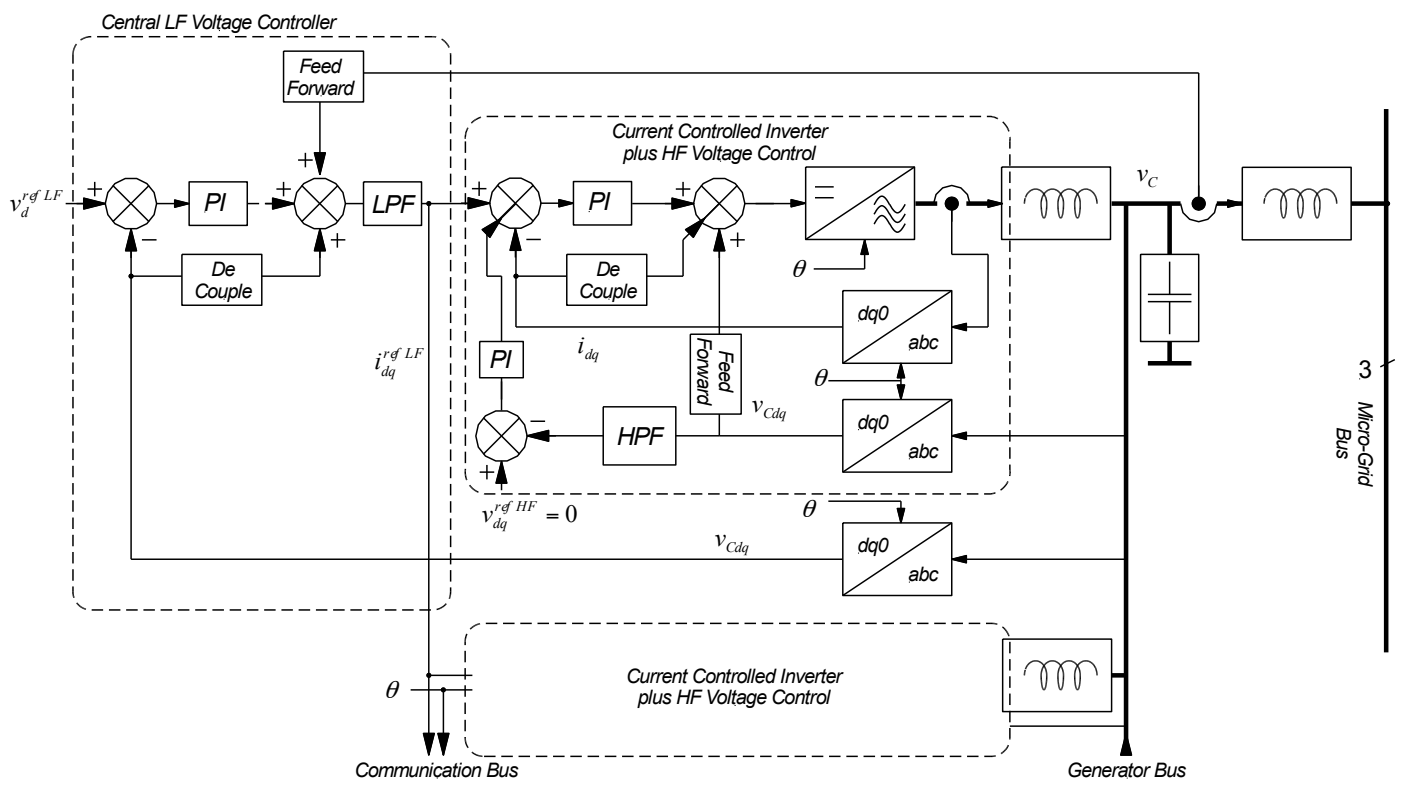

Figure 9. Distributed Control using Frequency Partitioning

There are some weaknesses in the control scheme that need to be guarded against in implementation. The control is distributed but relies on one control-loop for the most important feature of voltage control. This leaves the system open to a single-point failure mechanism despite its modularity. The voltage control-loop could be implemented in each inverter such that any inverter is able to assume this duty should one inverter fail. A second weakness is that the feed-forward term assumes that the total load current can be measured. In a power park of several generators in close proximity feeding one or two master busses this may be possible; in other circumstances it may not. The feed-forward term is not essential but does improve transient voltage performance proving noise and accuracy issues are addressed.

\subsection{Mixed Networks}

The distributed control scheme was not designed explicitly to incorporate traditional electrical machines as peers of the inverters. There are two approaches that could be used to form a mixed network. If the inverters dominate the network then distributed control could be used to establish an isochronous network. A synchronous machine can then be run up and synchronised to it. The machine will run as a constant power device with the power set by the combination of its governor settings and the choice of reference frequency for the inverter controller [15]. Alternatively, if the electrical machines dominate then they can form a micro-grid and the inverter can be controlled in grid connected mode. The inverter can be set to run in constant (dispatched) power mode or given a power demand derived from the system frequency in a manner that mimics a governor droop characteristic.

\section{Experimental Results}

The experimental rig was built with an inverter of $10 \mathrm{kVA}$ and was connected to the $50 \mathrm{~Hz}$ voltage grid via a $\Delta$-Y isolating transformer (rated at $10 \mathrm{kVA}$ and with the $\Delta$-winding connected to the grid and with a voltage ratio of $415 \mathrm{~V} / 208 \mathrm{~V}$ ). The inverter parameters were: switching and sampling frequencies, $8.192 \mathrm{kHz}$, current control-loop bandwidth $1.9 \mathrm{kHz} ; \mathrm{C}=50 \mu \mathrm{F} ; \mathrm{L}=1.35 \mathrm{mH}$. The isolating transformer parameters were: $R_{S}=20 \mathrm{~m} \Omega ; L_{S}=100 \mu \mathrm{H} ; R_{M}=1 \mathrm{k} \Omega$ and $L_{M}=100 \mathrm{mH}$. Control systems and pulse-width modulators were implemented on a TMS320LF2407 in discrete-time form. The processor is also used to monitor several signals within the control blocks and make these available for recording by an oscilloscope via digital to analogue converters.

\subsection{Grid Connected Mode}

Figure 10 shows the response of the power exported to the grid when the demands are subject to step changes. Both the real and reactive powers are closely regulated through the action of the current control loops. Because the loops are in $d q$-form and the natural coupling is cancelled, the real power is not perturbed when the reactive power is stepped (and vice versa). The public grid voltage available in the laboratory is slightly distorted and 
unbalanced so the exported power shows a small ripple. As noted in section 4.1, it is possible to suppress this ripple but only by introducing distortion to the current.

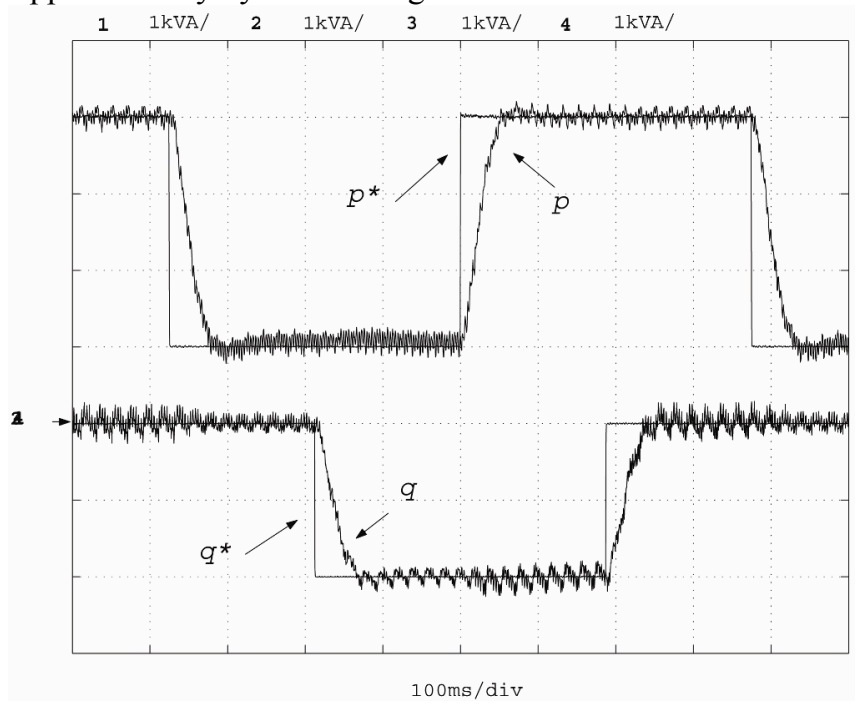

Figure 10. Response of Real and Reactive Powers to Step-Changes in Demand

Figure 11 show the pre-existing distortion of the available grid voltage and in particular significant $5^{\text {th }}$ and $7^{\text {th }}$ harmonic distortion. Figure 12 shows the current flowing into the grid. It has a similar degree of low order harmonic distortion despite the high impedance of the inverter in this frequency range. The harmonic current is being driven by the grid voltage harmonics through the capacitor of the inverter's filter. A voltage-source generator would present a much lower impedance to voltage harmonics and larger harmonic currents would flow. Figure 12 reveals some resonance lift at around $2 \mathrm{kHz}$ that results from the inability of the controller to suppress completely the resonance of the filter. Figure 13 shows the current over a wider frequency range and demonstrates adequate attenuation of the switching frequency components to more than $60 \mathrm{~dB}$ below the fundamental component.

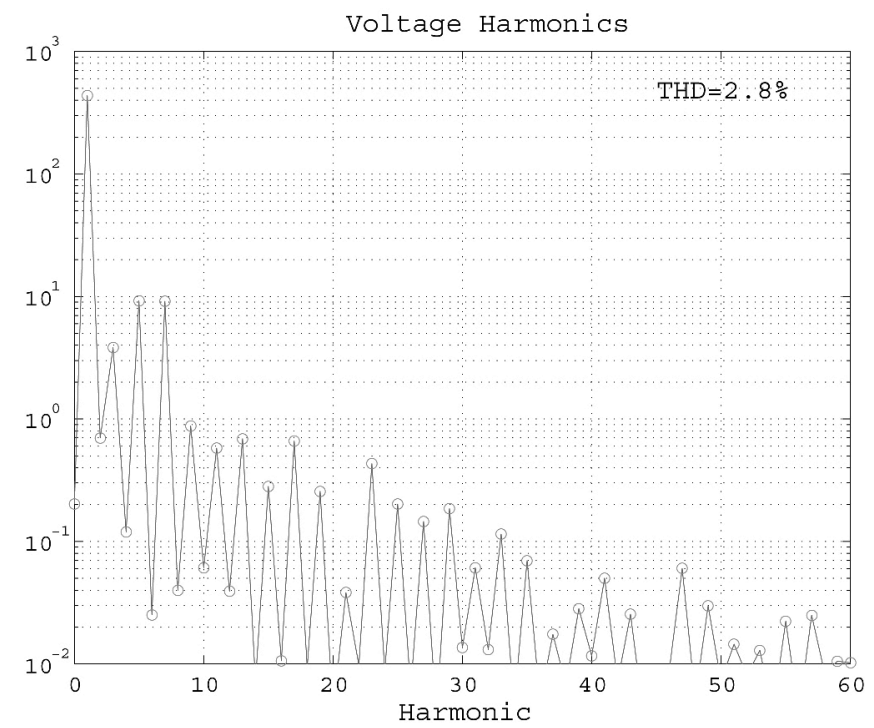

Figure 11. Grid voltage showing pre-existing grid distortion 


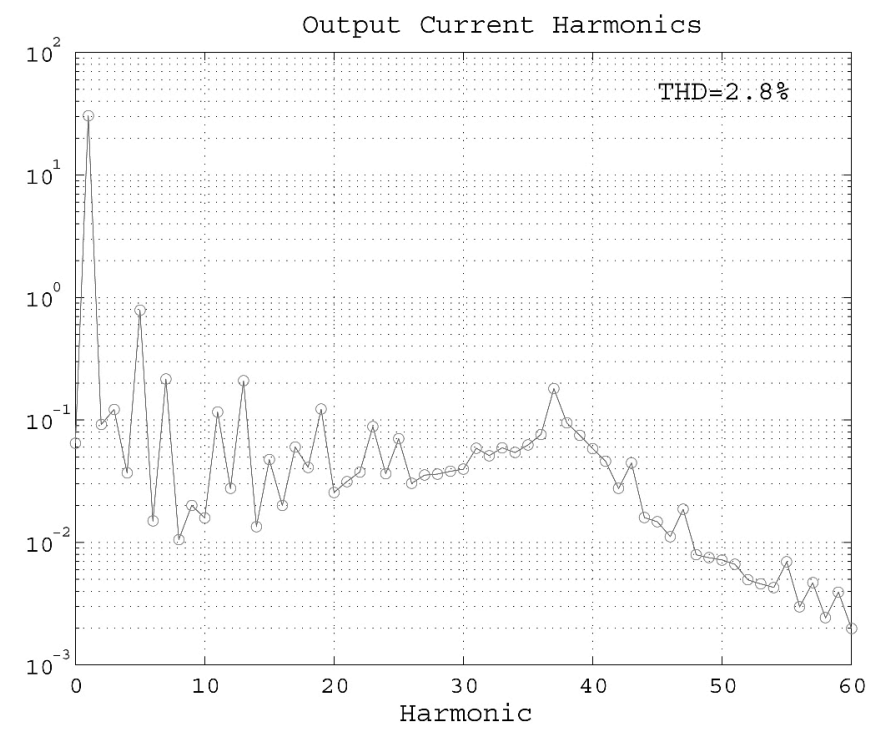

Figure 12. Exported grid current showing low-order harmonic distortion corresponding to the voltage distortion

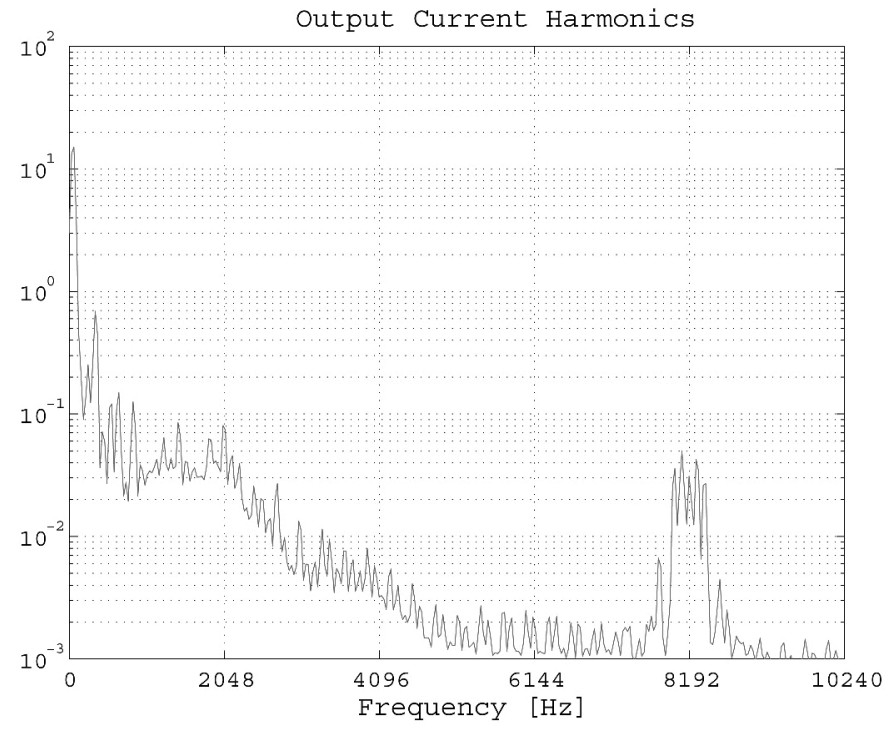

Figure 13. Exported Current shown over a frequency range including the switching frequency.

\subsection{Island Mode}

Three of inverters (30kVA system) running the distributed control algorithm were connected to a variety of linear and non-linear loads in both steady-state and transient conditions. Figure 14 demonstrates that the voltages are reasonably free of both switching frequency and low-order harmonic distortion. The total harmonic distortion was calculated as $1.32 \%$. This is largely due to the limited ability to suppress distortion in the region of the filter resonance because of the limited control bandwidth. A micro-grid is likely to supply several singlephase loads and load imbalance must be anticipated. Figure 15 shows that the voltage controller maintains reasonable balance in the presence of a pure single-phase load. A disadvantage of control in a synchronously rotating reference frame (compared with control in a stationary frame) is that imbalance is more difficult to control. Notwithstanding this the resulting negative sequence and zero-sequence imbalance in voltage were only $2.9 \%$ and $1.3 \%$. The voltage THD remained at $1.3 \%$. The closed-loop voltage control will give good voltage 


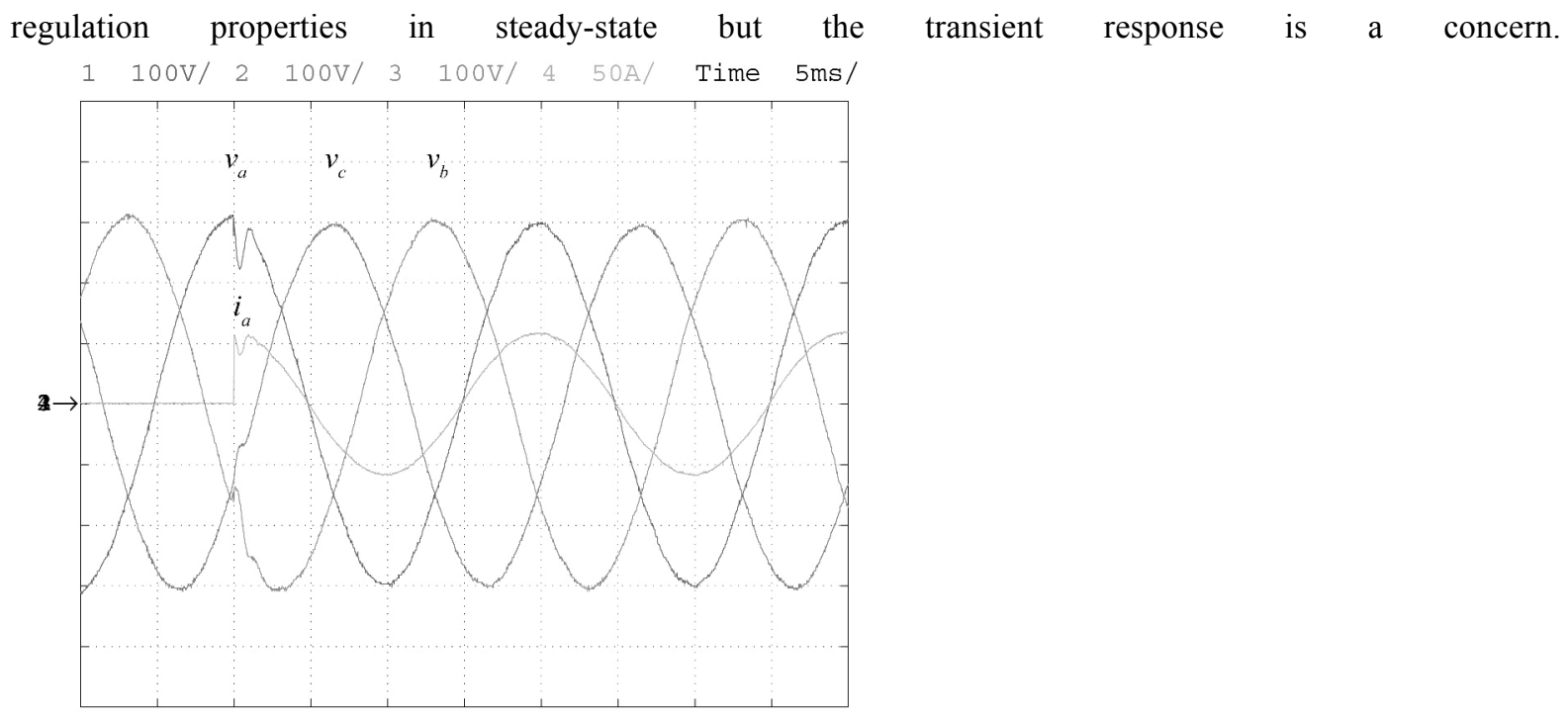

Figure 16 shows that the transient response of the voltage is well-damped and lasts less than $2 \mathrm{~ms}$.

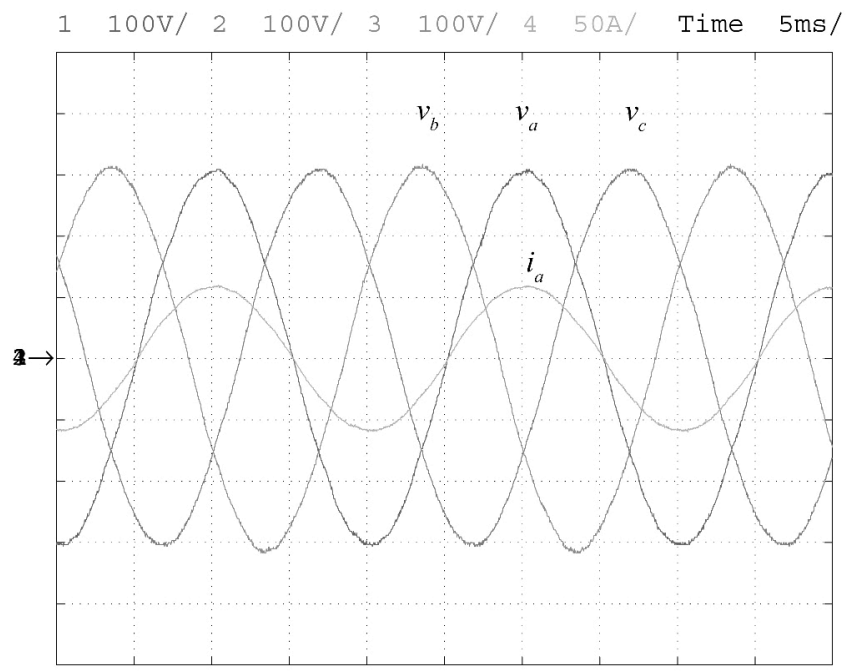

Figure 14. Phase-voltages under 1.0 p.u. resistive load. THD is $1.32 \%$ 


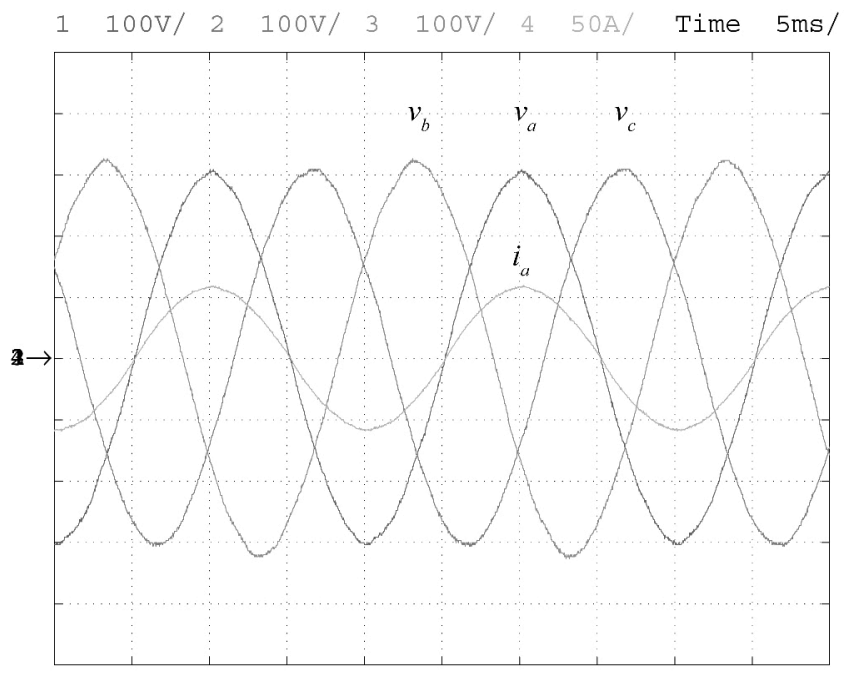

Figure 15. Phase-voltages under 1.0 p.u. single-phase load. $2.9 \%$ and $1.3 \%$ of voltage negative and zero sequence imbalance. THD is $1.32 \%$

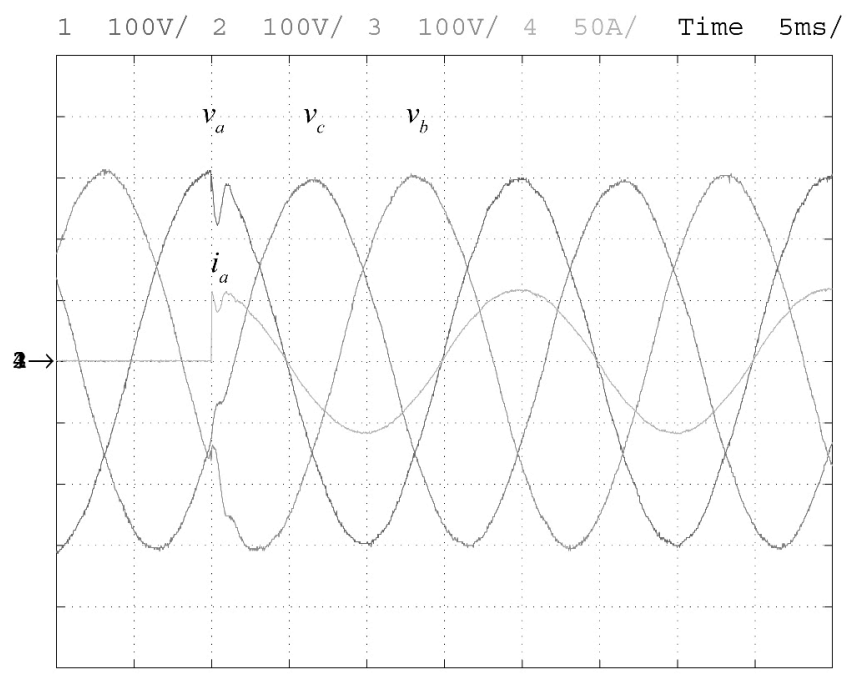

Figure 16. Phase-voltage and phase-current with step application of 1.0 p.u. single-phase load.

Loads in domestic and commercial environments are likely to contain many uncontrolled diode rectifiers (although IEC 1000 will put a halt to the growth of the worst of these devices). Figure 17 shows the phase current drawn by a typical single-phase rectifier (e.g. a group of PCs). It is clear that the waveform has a very high crest factor, high harmonic distortion and low power factor. Although the real power load is only 0.25 p.u., the current peak is 0.7 p.u. The phase-voltage shows the common distorted profile experienced in many distribution systems. Figure 18 confirms the presence of considerable harmonic distortion in the phase voltage, principally $3^{\text {rd }}$ and $5^{\text {th }}$ harmonics as a result of the current harmonic demand. 


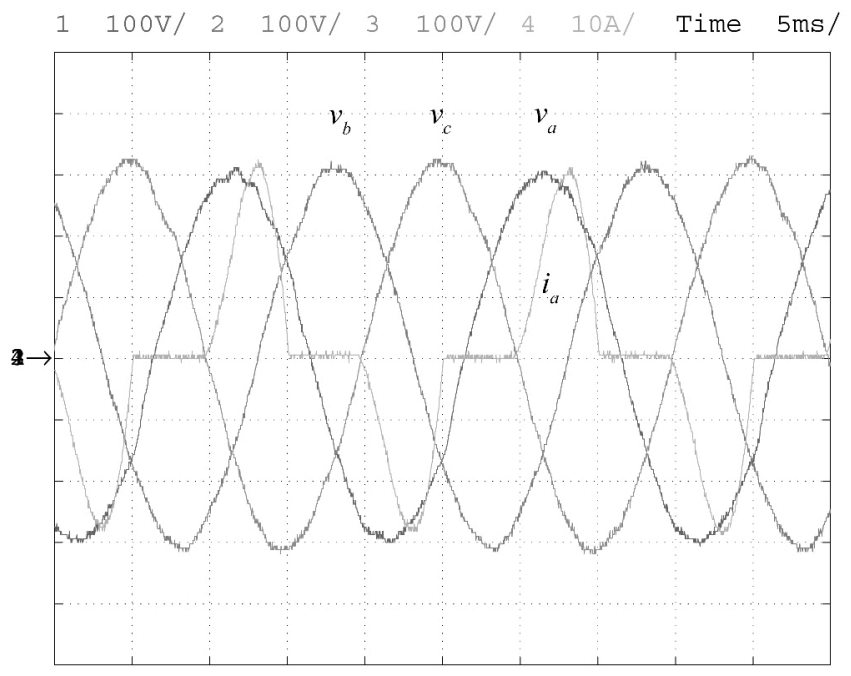

Figure 17. Phase-voltage and phase-current with non-linear (single-phase diode rectifier) load of 0.25 p.u.
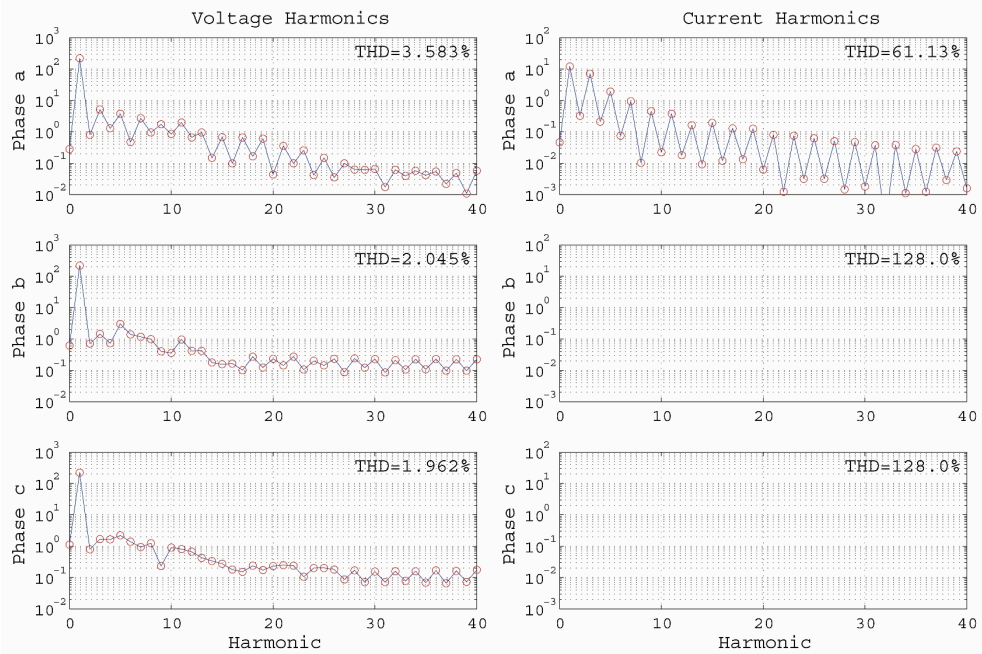

Figure 18. Frequency spectrum of phase voltage under 0.25 p.u single-phase non-linear load

\section{Conclusions}

Island mode operation of an inverter has been demonstrated in a control scheme specifically designed to accommodate parallel operation and to exploit the controllability of an inverter to deal with distorting loads. The parallel operation scheme has been designed to use low-bandwidth communication channels. Although communication is not absolutely necessary, its provision does allow for better sharing of duty in transient conditions. The control bandwidth of an inverter is limited by the switching frequency and the discrete nature of the control system. However there is sufficient bandwidth to control actively the low-order harmonic disturbances (from non-linear loads).

\section{Acknowledgements}

The work described arises from projects supported by Turbo-Genset PLC, Engineering and Physical Science Research Council (UK) (GR/N38190/1) and the European Commission.

The European Commission support is under the 5th Framework Programme and contributing to the implementation of the Key Action 5 "Cleaner energy systems, including renewables" within thematic programme Energy, Environment and Sustainable Development - Contract No. ENK5-CT-2001-00522, project DISPOWER. We are solely responsible for this work, it does not represent the opinion of the European 
Community and the European Community is not responsible for any use that might be made of data appearing therein.

\section{References}

1 R.H. Lasseter, “MicroGrids", IEEE Power Engineering Society Winter Meeting, 2002, Vol. 1, pp. 305 -308, 2002

2 C. Marnay, F.J. Robio and A.S. Siddiqui, "Shape of the microgrid", IEEE Power Engineering Society Winter Meeting, 2001, Vo. 1, 2001, pp. 150 -153, 2001

3 G. Venkataramanan and M. Illindala, "Microgrids and sensitive loads", IEEE Power Engineering Society Winter Meeting, 2002, Vol. 1, pp. 315 -322, 2002

4 A.T. Wojciech, M.M. Jovanović and F.C. Lee, "Present and Future of Distributed Power Systems" IEEE Applied Power Elec. Conf. (APEC `92), pp. 11-18, 1992

5 T.C. Green, 'Impact of EMC directive on power converter designs', IEE Power Engineering Journal, Vol. 8, No. 1, pp. 35-43, 1994

6 N.Bruyant and M. Machmou, "Simplified digital and analogical control of shunt active power filters under unbalanced conditions”, IEE Power electronics and variable speed drives conference (PEVD '98), pp. 1116, September 1998.

7 M. Prodanović and T.C. Green, "Power Quality Improvement in Grid Connection of Inverters". IEE PEMD Conference, Bath, Conf. Pub. No. 487, pp. 24-29, April 2002

8 M. Prodanović and T.C. Green, "Control and Filter Design of Three-Phase Inverters for High Power Quality Grid Connection", IEEE Trans on PE, Special Issue on Digital Control (accepted for publication)

9 J. Liang, T.C. Green, G. Weiss and Q.-C. Zhong, "Evaluation of repetitive control for power quality improvement of distributed generation", IEEE Power Elect. Specialist Conf. PESC '02, Cairns, June 2002

10 Mohn, Underland and Robins, Power Electronics, $2^{\text {nd }}$ Ed., Chapter X,

11 Murphy and Turnbull, Power Electronic control of AC machines, Pergamon Press 1988

12 T.C. Green, M.H. Taha, N.A. Rahim, and B.W. Williams, 'Three-phase step-down reversible AC-DC power converter', IEEE Trans. on Power Elect., Vol. 12, No.2 ,pp. 319-324, 1997

13 M. Prodanović and T.C. Green, 'Comparison of Control Strategies of Parallel Connection of Inverters to a Distribution Grid', Power Electronics and Variable-Speed Drives Conference (PEVD 2000), IEE Conf. Publ. No. 475, London, U.K., pp. 472-477, September 2000

14 K. Siri, Q. Lee and T.F. Wu, "Current distribution control for parallel connected inverters", IEEE Trans. Aerospace and Electronic Systems, Vol. 28, No. 3, pp. 829-851, 1992

15 L.L.J. Mahon, Diesel Generator Handbook Chapter 8, Butterworth-Heinemann Ltd., Oxford (UK) 1992 